\title{
Establishment of Undergraduate-education Class Adviser Teams on the Governance Theory Perspective
}

\author{
Jun-ao Chen \\ School of Marxism, East China University of Science and Technology University, \\ Shanghai, 200237, China;
}

Keywords: Governance theory; undergraduate education; class adviser teams; establishment

\begin{abstract}
Governance theory is of great referential significance to the establishment of undergraduate education class adviser teams. It is decided by the multiple participants, diversified fields and complex constitution of the undergraduate education class adviser teams. Both the establishment of the undergraduate education class adviser teams and the governance theory have the characteristics of consistent goals, interactive processes, coordinated ways, etc. In other words, there are internally unified logic relations between the establishment of the undergraduate education class adviser teams and the governance theory. Therefore, to successfully establish the undergraduate education class adviser teams from the perspective of the governance theory, we must cultivate the governance concept of the participants, build the governance mechanism for the establishment of the undergraduate education class adviser teams and set up the governance platform for the establishment of the undergraduate education class adviser teams.
\end{abstract}

\section{Introduction}

It is pointed out in the Decisions made by the Central Committee of CPC on Comprehensively Deepening Reform and other Major Issues that "aiming to safeguard the fundamental interests of the overwhelming majority of the people, we must, to the utmost extent, increase harmony factors, boost vitality of social development, advance level of social governance and innovate social governance.” Social governance has become an important idea and channel to deepen reform of Chinese society. The governance theory is applicable to not only social governance and governmental governance, but also internal establishment and optimization of organization. In the circumstances, the establishment of the undergraduate education class adviser teams is important part of undergraduate education. We can strengthen the vitality and working competence of undergraduate education class adviser teams and improve the level and quality of undergraduate education by referring to the idea of governance theory[1].

\section{Internal Logic Relations Between Governance Theory and the Establishment Undergraduate Education Class Adviser Teams}

\subsection{Consistent goals}

According to the governance theory, the precondition and basis for governance are specific and consistent goals. "Governance is supported by common goals." The participants of governance have their own goals which are diversified. Governance means to establish the common goals accepted and supported by all the participants by consultation and interaction among them. Therefore, "consistent goals can reduce the quantity and strength of conflicts among members and then improve the overall coordination of organization”. As an important part of undergraduate education, the participants in the establishment of class adviser team include undergraduate education class advisers, undergraduate education institutes, undergraduate education students, undergraduate education course teachers, related undergraduate education departments in schools, etc.[2] These participants have their own targets and interests, but they have the common goals to strengthen the vitality and working competence of undergraduate education class adviser teams and to improve the quality of undergraduate education. These consistent goals constitute the precondition and basis for all the undergraduate education participants to jointly establish class adviser teams. 


\subsection{Interactive processes}

Interactive processes are the essential feature of governance. "Governance isn't a formal institution. In fact, it is continuous interaction." Instead of one-way power movement, governance is actually an up-and-down interactive management process which achieves the goals set by the organization mainly by consultation, cooperation, recognition, achievement of common goals, etc. among the participants. To fulfill the establishment of undergraduate education class adviser teams, constant interaction among the participants is essential [3]. This kind of interaction is reflected in: interaction and sharing of management experience, working experience, etc. among insiders of the class adviser teams; interaction between students and class advisers of undergraduate education, feedback on learning experience given by students to class advisers, management thoughts delivered by class advisers to students; interaction between institutes and class advisers of undergraduate education, policies, rules and regulations on undergraduate education transferred by institutes to class advisers, problems in the management process reported by class advisers to institutes; interaction between course teachers and class advisers of undergraduate education, class situations reported by course teachers to class advisers, specific situations of students reported by class advisers to course teachers; interaction between related undergraduate education departments in schools and undergraduate education institutes, etc. This kind of constant interaction in the management process of undergraduate education is the basic condition to facilitate the establishment of undergraduate education class adviser teams [4].

\subsection{Coordinated methods}

Coordinated methods are the necessary conditions for governance. In the process of governance, application of methods is vital. To realize the governance goals, the participants in governance have to establish coordinated ideas, keep effective communication and carry out constant coordination according to the governance process so as to create favorable conditions and environments for the implementation of governance and the realization of governance goals. Coordination can encourage the participants in governance to have consistent steps, unified thoughts and specific goals in the process of governance. Therefore, the establishment of undergraduate education class adviser teams should also be carried out by coordinated methods [5]. The constitution of undergraduate education class adviser teams is very complicated. To be more specific, most class advisers of undergraduate education are teachers who are back to work after retirement. Without high academic qualifications, they only have limited management competences and levels. Under such circumstances, related undergraduate education departments in schools and undergraduate education institutes should spend more time on communicating with the class advisers to make them truly understand and support the management systems and stated goals of undergraduate education. At the same time, in the course of undergraduate education, all the participants should strengthen communication and coordination, unify ideas, understand and support each other to reach the goals of undergraduate education.

\section{Reasons Why Governance Theory Is Essential in the Establishment of Undergraduate Education Class Adviser Team}

\subsection{The multiple participants in the establishment of undergraduate education class adviser team require governance theory}

The establishment of undergraduate education class adviser teams aims to improve the quality of class advisers and advance the vitality and management ability of the teams. In this process, it covers members of the class adviser teams, undergraduate education institutes, related undergraduate education departments in schools, course teachers, undergraduate education students, etc.[6] Even though these participants play different roles in the establishment of undergraduate education class adviser teams, they need to help and depend on each other. Therefore, the characteristic of multiple participants is presented obviously. The undergraduate education class advisers are the subjects and objects of the team establishment. Consequently, in the establishment of class adviser teams, each undergraduate education class adviser should actively adapt to the trend of modern undergraduate education, carefully learn the theory of modern undergraduate education 
and improve their all-around quality and working competence[7]. Undergraduate education institutes are the instructors and supervisors in the establishment of class adviser teams. They are obliged to specific team establishment directions, standardize the contents of team establishment, etc. Besides, related undergraduate education departments in schools, course teachers and undergraduate education students are the external participants in the establishment of class adviser teams. As important factors in the establishment of undergraduate education class advisers, they can provide valuable suggestions on team establishment, offer ideas for team establishment, etc.

\subsection{The diversified fields in the establishment of undergraduate education class adviser teams require governance theory}

The establishment of undergraduate education class adviser teams covers diversified fields [8]. The establishment of undergraduate education class adviser teams is divided into establishment of internal quality of teams, external establishment of teams, and cultural establishment of teams and so on. Firstly, the internal establishment of teams requires governance theory. The internal establishment of teams includes establishment of quality of class advisers, establishment of the setting of class advisers, etc. In the process of the internal establishment of teams, to achieve the consistent goals in the team establishment, we need not only guidance from the superior departments of class adviser teams, but also constant exchanges, analyses and interaction among class advisers. Secondly, external establishment of teams requires governance theory. In the external establishment of teams, we should keep in close contact with undergraduate education students, course teachers, related undergraduate education departments in schools, etc. In addition, class advisers and related subjects should keep close contact with each other and make contributions to the cultivation of excellent undergraduate education students through communication and coordination. Thirdly, the cultural establishment of teams requires governance theory. In the cultural establishment of teams, insiders and outsiders of teams should closely cooperate with each other and set the goals to serve students and achieve national undergraduate education as the underlying value orientation towards cultural establishment.

\subsection{The complex constitutions of undergraduate education class adviser teams require governance theory}

According to the current state of undergraduate education class adviser teams, the constitutions of teams are very complex. The complexity is mainly reflected in: severely aging class adviser teams, old management ideas and incapability to supervise students by modern informatization means; class adviser teams' lack of high academic qualification, shortness of competence and weak service awareness in general; lack of assessment and incentive measures, as well as shortness of standard management systems for class adviser teams, etc. The complexity of the constitutions of undergraduate education class adviser teams is the huge obstacle to the realization of the undergraduate education goals. The complex constitutions of undergraduate education class adviser teams require us to consider issues from the perspective of governance, constantly absorb ideas of class advisers through continuous communication and coordination, arouse class advisers' passion for work by establishment exchange platforms and make class advisers gain self-growth in the activities of team establishment.

\section{Concept of the Establishment of Undergraduate Education Class Adviser Teams from the Perspective of Governance Theory}

\subsection{Cultivation of the governance concept of participants}

Concepts are the forerunners of actions. From the perspective of governance theory, the precondition for the establishment of undergraduate education class adviser teams is the governance concept formed by all the participants. In other words, before the establishment of undergraduate education class adviser teams is carried out, the governance concept of all the participants should be cultivated. To be more specific, we need to make the participants form the concept of consistent goals and interactive coordination.

The core goal of the establishment of undergraduate education class adviser teams is to enhance the cohesion of teams and develop excellent class advisers. This goal is not only class advisers' demand for self-development, but also the fundamental value of the establishment of undergraduate education class 
adviser teams. Therefore, if the participants don't reach a consensus on this goal, the establishment of undergraduate education class adviser teams from the perspective of governance theory can't be implemented. In other words, the concept of consistent goals is the principal factor of the governance concept.

To reach the goals in the establishment of undergraduate education class adviser teams, interactive coordination is the key. To achieve interactive coordination, firstly, we should establish an interactive mechanism. The participants should continuously interact with each other on the specific issues about the establishment of class adviser teams to lay a solid foundation for the achievement of consistent goals. Secondly, we should establish a coordination mechanism. In face of the issues in the establishment of class adviser teams, the participants should correct wrong concepts and reach consistent goals by actively communication and consultation. Based on the concept of consistent goals, this interactive coordination concept is guided by the governance theory. Therefore, the interactive coordination concept is fundamentally different from the previous interactive coordination that was advanced independently.

\subsection{Construction of the governance mechanism for the establishment of class adviser teams}

The key point of the establishment of undergraduate education class adviser teams from the perspective of governance theory is the construction of governance mechanism. "Mechanisms are ways of interactions and mutual effects among different parts of social organisms.” By certain modes of operation, a mechanism can make organizations play larger overall functions. To achieve the goals of the establishment of undergraduate education class adviser teams, we should build a governance mechanism for team establishment in the aspects of vitality and teaching.

Firstly, we should establish a vitality mechanism for undergraduate education class adviser teams. The core task of the establishment of undergraduate education class adviser teams is to improve the vitality and strengthen working competence of teams. At present, both the theory and practice of the establishment of undergraduate education class adviser teams have proved that the construction of the vitality mechanism for undergraduate education class adviser teams is the results of the common work of all the participants and that corresponding governance structure plays an important role in the construction of the vitality mechanism. Under the vitality mechanism, an excellent undergraduate education class adviser team has full vitality and strong working competence; the superior management departments give forward-looking guidance and other participants make inspiring suggestions.

Secondly, we need to establish the teaching mechanism for undergraduate education class adviser teams. The nature of the establishment of undergraduate education class adviser teams is to improve quality of class advisers and strengthen working competence of them. To play the functions of the teaching model of undergraduate education class adviser teams, we can't simply depend on class advisers. To be more specific, in the establishment of class adviser teams, we should play the functions of undergraduate education institutes, related undergraduate education departments in schools, course teachers, undergraduate education students and other participants; construct a set of teaching mechanisms where functions are played mainly by undergraduate education class advisers with the help of other participants.

\subsection{Governance platforms on the establishment of class adviser teams}

Governance platforms are the important carriers for the establishment of undergraduate education class adviser teams. Therefore, we should integrate various resources and establish online and offline governance platforms to provide carriers for the establishment of undergraduate education class adviser teams.

We should establish technological and practical online governance platforms on undergraduate education class adviser teams on the purpose of promoting quality and class advisers and strengthening working competence of class advisers. On the one hand, online governance platforms should adopt the latest and most advanced network technology achievements, such as WeChat, microblog, big data, etc. On the other hand, to establish online governance platforms, we need to consider the actual situation of the establishment of undergraduate education class adviser teams and meet appeals all the participants to make it convenient for them to participate the establishment of online governance platforms.

The establishment of governance platforms on undergraduate education class adviser teams should highlight resources integration and actively play the roles of participants. The undergraduate education class adviser teams only have limited resources. Therefore, in practical work, we should make use of various 
resources inside and outside schools to build all kinds of governance platforms. In the establishment of governance platforms for undergraduate education class adviser teams, we should not only pay attention to resources integration, but also encourage participants to play their roles actively. To be more specific, we can facilitate the establishment of governance platforms on undergraduate education class adviser teams by building corresponding institutional guarantee, issuing honor, arousing enthusiasm of participants.

\section{Summary}

Class adviser is an important part of undergraduate-education class adviser team, the backbone of undergraduate-education work engaging in moral education, carrying out students' ideological and political education work, the guide for students' healthy growth, and an indispensable and important force for the construction of contemporary harmonious undergraduate-education. Class advisers in the new era are facing new development opportunities and severe challenges. Only through comprehensive reform can they meet the development needs of the society and students. Therefore, by introducing the governance theory, the governance model of undergraduate-education class adviser is reconstructed to provide a decision-making reference for the construction of undergraduate-education class advisers.

\section{References}

[1]. Xi Jinping. Better and fairer education for the 1.3 billion Chinese people. The governance of China volume I. [M]. 2014:211.

[2]. Feng wei. The class teacher plays a special role in the psychological adaptation of college freshmen[J].Contemporary education BBS,2003,(10):76-7.

[3]. Tiantang Qin. The professionalization and specialization of counsellors from the perspective of role conflict [J]. Journal of Nanjing Forestry University. 2009(04)

[4]. H Thiry, SL Laursen. The role of student-advisor interactions in apprenticing undergraduate researchers into a scientific community of practice [J]. Journal of Science Education and Technology, 2011Springer.

[5]. Li Lin. Research of University Classroom Teaching Quality Standard [J]. China Standardization, 12 (2012) 18-20

[6]. GD Kuh, J Kinzie, JH Schuh, EJ Whitt. Student success in college: Creating conditions that matter. 2011,books.google.com

[7]. Weixiong Huang. On the difficulties and countermeasures of head teachers' management in adult colleges and universities [J]. Journal of Jiamusi vocational college, 2016(05):273-274.

[8]. Lin Li, Yiwei Li. Evaluation and Research of Management Methods of Chinese Universities' Undergraduate Education Quality [J]. Advances in Social Science, Education and Humanities Research, volume 101(ICEMCT 2017) 